\title{
Ventures Within Fisheries Value Chain that Men and Women Participate in Nairobi City County, Kenya
}

\author{
Paul Kizito \\ Department of Gender \& Development Studies, Kenyatta University
}

\begin{abstract}
Elishiba Kimani
Department of Gender \& Development Studies, Kenyatta University. also serves as Associate Dean, of the Graduate School, Kenyatta University
\end{abstract}

\section{Mildred Lodiaga}

Department of Gender \& Development Studies, Kenyatta University; also serves as Chairperson, of the Department of Gender \& Development Studies, Kenyatta University

\begin{abstract}
The government of Kenya has put in place an integrated package of service to reduce gender disparities through credit facilitation, which includes business skills, enhanced and increased access to the viable markets among others. It is in this respect that this study sought to establish the status of men and women in the entrepreneurial fisheries activities in Kenya; with an objective to establish various ventures within fisheries value chain that men and women participate. The social structural theory developed by Connell (1987) based on patriarchal system and social mechanisms in place to reinforce and sustain the ideology. The theory provides a substantive justification of women's subordination in the fisheries value chain. The study findings showed that men were prominent in economically high end City market and South $\mathrm{C}$ market while women were more in the marginal Kariobangi market. The findings revealed that men had controlled the high-end value chains namely; aquaculture/fish harvesting, transportation, distribution, middle trade, and large scale while women were more focused on the lower end value chain namely; grading/sorting/gleaning and market sellers.
\end{abstract}

Keywords: Gender, participation, value chain, gender division of labour, sex division of labour Cathexis

\section{INTRODUCTION AND CONTEXT OF THE STUDY}

Participation in fisheries value chain contributes to socio-economic development, improvement of livelihoods and reduction of poverty (Wangila et al., 2007). Fisheries value chain is the process of bringing fish from harvesting through different phases of processing and delivery to the consumer. This process involves various economic utilities such as form, place, time and possession, which have attracted various actors and stakeholders such as governments, international agencies and credit institutions as a strategy of mobilizing economic resources to promote small scale traders and improve the household's livelihood. Although men and women participate in various ventures within the fisheries value chains; women have been restricted to less competitive form utility that has impacted on their level of access and control of fisheries resource. This has been influenced by socio-cultural and economic factors such as gender roles, culture, values, attitudes and norms (Williams, 2002; FAO, 2013). The higher levels of the value chain earn men higher commercial and economic potentials while women at lower levels operate with restricted economic margins. World Bank 
(2013) has thus emphasized the need for development policies, programmes and donor agencies to support women economic activities and especially in agricultural value chains.

In Africa; (Shalesha \& Stanley, 2000; 2001; Mafimisebi, 2007), affirm that, the control of land, capital, labour and competitive economic utilities exhibits patterns similar to the agrarian communities, where patriarchal structure takes precedence; hence, women are excluded from the profitable segments and competitive economic utilities of the value chain. Although women's roles are noticeable in fisheries sector as marketers and processors; their limited economic potential to viable economic utilities, has subordinated them in the value chain. The women's offshore fisheries production trends have been reported in regions of developing countries such as East, South and West Africa, their place in control of viable economic utilities in the fisheries value chain has remained subordinate (Mafimisebi et al., 2009).

In Kenya, women occupy a central place in the fishing sector representing $70 \%$ to $87 \%$ of fishworkers involved in artisanal fish trade (Ogutu, 1988; \&, 1992). Although fisheries market chain is characterized by a high participation of women; often single, divorced and widowed, their participation in the value chain exhibits lower economic potentials (Ogutu, 1992; Medard \& Wilson 1996; Geheb1997; Lwenya \& Abila 2000). According to (Geheb 1997), control of fisheries resource in the value chain is a task allocated to men, while women are usually engaged more in the post-harvest activities such as smoking, drying, and marketing for subsistence. This level of participation earns women a narrow profit margin as compared to that earned by the men who control the resource. The level of education, culture, values, attitudes and norms are fundamental factors that may have influenced the women's lower end fisheries value chain and further served as informal regulatory mechanism, which influence access and control of the resource (Geheb 1997).

Women in fisheries value chain in Nairobi City County comprise a significant majority yet least in ranking as far as access and control of economic utilities are concerned. The rationale for this circumstance is based on the systemic prejudice and discriminatory policies, financial constraints, socio-cultural and educational factors that limit women's access to entrepreneurial resources (Ogutu, 1992). The implications of this are the evidence of the discrepancies between men and women at the level of performance in the fisheries value chain based on control of productive resources by men; hence, women continue to operate under difficult socio-cultural and economic environment (Ogutu 1992; Nayak 2000).

Amidst this scenario, the government of Kenya in collaboration with the fisheries stakeholders has incorporated gender issues into the national instruments, policies and legislations. Support has focused on the improvement of women's access to credit facility; strengthening administrative action by ensuring that male and female fisheries extension officers are recruited and given gender awareness training. In addition, capacity building for men and women in entrepreneurial value chain on appropriate ways of fish processing (McCormick, 2001). It is against this background that this paper sought to understand various ventures within fisheries value chain that men and women participate in Nairobi City County, Kenya. It is fundamental thus for this paper to respond to this question: What are the ventures within the fisheries value chain that women and men participate?

\section{METHODOLOGY}

Nairobi City County was purposively selected due to the fact that within this area there are high number of value-chain based livelihoods; with a high concentration of infrastructures and 
credit institutions that focus on improving small scale trade and entrepreneurship. Data was collected from three market areas of Nairobi City County; (City, South C-Mugoya and Kariobangi markets). These were selected on the basis of the principle of distributive justice for samples selected to exhibit a proportional representation of different economic carders, the study focused on three (3) zones within Nairobi City County based on the socio-economic characteristics as: affluent class, middle class and lower class (The World Bank: World-stat info, 2013). One market was selected from the city and two other markets from its environs as a representative of the class distinctiveness and to capture opinions from diverse socioeconomic characteristics within Nairobi City County. The respondents included men and women within fisheries value chain in Nairobi City County; personnel from the Ministry of Agriculture, Livestock and Fisheries; and the City Council of Nairobi assigned to the market areas purposively sampled for study within Nairobi city totaling to the sample of 390 . The data was collected using guided questionnaire and Focus Group Discussions. In addition interviews were conducted particularly to key informants (personnel from the ministry and those in Nairobi City County). The secondary sources have been used.

\section{THEORETICAL FRAMEWORK}

Studies on ventures within fisheries value chain have focused mostly on fish harvesting, gender roles in fisheries sector and post-harvesting processing (De Silver, 2011; FAO, 2008; Kohl et al., 2002). There are limited studies on specific ventures in fisheries value chain that men and women participate. This paper intends to fill this gap.

Studies have shown that men and women participate in complementary activities in fish harvesting (Lyne, 1999; De Silver, 2011). Although women are involved in the fisheries related economic activities, their representation in the control of resources related to the sector and high end value chain is negligible. For this reason, socio-economic and cultural factors, which determine participation of men and women in fish harvesting are rooted in gender stereotypes. According to Ajagbe (2012), women are involved in fish harvesting for subsistence while men for commercial purposes. Thus, men are culturally associated with commercial and large-scale activities as women remain in small scale, subsistence and non-commercial fish harvesting. In Kenya, status of women in fisheries sector has not been adequately studied, an inspection on representation by men and women in fish harvesting revealed a disparity; where harvesting and control of fisheries resources were known as a predominant occupation of men as this paper attempts to explore. According to Kronen (2003) in fishing communities, women mainly participate in post-harvest and processing activities. Medard et al., (2000) argued that such activities include smoking; drying and marketing earn women a narrow profit margin in the value chain compared to that earned by men. As Nwabeza, (2013) in a study on gender roles in the aquaculture production reported that in Nigeria, women form the core of the industrial fisheries labour force through their involvement in the post-harvesting and processing. Hence; some socio-cultural factors and taboos have reinforced involvement of women in the lower end value chain as processors within the context ascribed to the traditional division of labour.

Fresh fish distribution is largely a male domain. Women are generally excluded from involvement in transportation due to the belief that women have difficulties in adapting to the night-time hours worked in fish distribution. The women are considered to lack physical strength needed for the work and would not be able to work as hard as men. Distribution and transportation are usually done at night, which makes women involvement difficult. The culture and customs did not allow women to work at night due to their household duties (Williams et al 2008). Williams et al., (2008; ILO 2008) further reports that women combine fish trade with other trading activities, which affirm the magnitude of their small-scale 
operations and the demand for diversification in addition to their prescribed traditional roles. Although $80 \%$ of traders in the fish marketing are women, their scale of operation is lower; hence, are compelled to trade the left-over, less profitable, juvenile fish and factory rejects (McCormick, 2001; Fauzi et al., 2010). The top decision-making bodies, which control and determine the market operations, have no representation of women, despite their significant time input and energy into the fish markets.

Connell, (1987) provides social structural theory based on the concepts of sexual inequality, which explains subordination, gender and power imbalances. The theory outlines the following three major structures that describe subordinate relationship between men and women in the worldview as: sexual division of labour, which examines economic inequalities that favour men; second; sexual division of power that examines inequality and abusage of authority and control that favour men and Cathexis, which examines socio-cultural norms and effective attachments based on the informal institutions (Connell, 1987). These three structures are rooted in the society through numerous historical, economic, cultural and socio-political forces, which define power and ascribe social norms on the basis of gender and culturally determined roles (Connell, 1987).

\section{STUDY RESULTS AND DISCUSSIONS}

Men and women engage in various ventures within the value chain in Nairobi City County. There are high end (fish harvesting, transport, distributors, large scale) and lower end value chains (grading/sorting/gleaning and market sellers). The findings indicated that activities entailed in high end value chain required control of multiple physical labour and financial input to own boats, nets and human resource, risks were involved; hence, not preferable amongst women actors. These findings implied that control of key potential value chains was associated to patriarchal structures, which placed women within the private segments; where sex division of labour was the determinant of the activities and roles allocation within fisheries value chain. As Connell (1987) argued, these findings suggested that customary laws have restricted women compared to men in access to and control over assets of production like land, which are assets as collateral to access credit for competitive investments. It was noted that this limitation has led to the alternative means of borrowing resources to acquire capital. The study reported that these included indigenous borrowing systems; where women obtained informal credit from relatives, money lenders and local group money collectors; with the self-initiated rotating credit associations as one of the most popular schemes. These alternative means were reported as not providing adequate resources for competitive investments in high end value chain. The following were found to be ventures of the value chain within fisheries sector in Nairobi City County.

\section{Fish Harvesting}

Fish harvesting was the prime and most important venture of the value chain. It was found that there were more men than women engaged in fish harvesting; and concentrated mostly in City market compared to South C-Mugoya and Kariobangi market areas. There were more men than women in fish harvesting as high end value chain in selected markets. Connell, (1987) argued that sex division of labour, inequality and authority that favour men were rooted in the society through numerous historical, economic, cultural and socio-economic forces, which define power and ascribe socio-norms on the basis of gender and culturally determined roles. The findings revealed that fish harvesting occurs at night, while the determinants involved ownership and control of boats, nets, going out at night into the seas, rivers, dams and lakes in 
search of fish resource, casting of the nets into the water and hauling fish into the boat and later at the beach.

These findings implied that fish harvesting was predominantly men's work, and the reason given was that it required a lot of time, energy and that it was a risky activity. The extensive financial requirement was found to have made fish harvesting an expensive activity being a reserve for men; while, cultural forces regarding ownership of property and freedom to engage into the masculine activities overnight have also kept women away from the aquaculture and fish harvesting. These findings implied that aquaculture and fish harvesting were socioculturally and structurally deliberate for men due to high economic potentials based on labour and capital requirements as shown in the focus group discussion:

The successful fish harvesting requires capital, labour for hauling, and control of the entire tasks involved in fish harvesting; ownership of boats, working overnight and often without clothes (Man, fish harvester and entrepreneur, FGD, South C-Mugoya Market. Date: 12th, September, 2014).

These findings are similar to Kamau and Ngugi (2013) in potentials for women fish traders and upgrade within the fish trade value chain who observed that gender division of labour characterized roles related to fisheries sector; harvesting was a preserve for men while women dominate handling, processing and marketing within the value chain. The focus group discussions established that traditionally actual fishing was considered prestigious and a man's role; with control of capital and labour for higher profit margins as confirmed by the following respondent in a focus group discussion:

Fishing requires more resources, freedom and time to be out of the home environment, which can be done by men only. (Woman participant in the FGD in Kariobangi market, $18^{\text {th }}$ September, 2014)

\section{Transportation}

The transportation of fish commodities was considered a high end entrepreneurial activity. This indicates that men were more involved in transporting fisheries products from lakes and dams to the selected markets. It was noted that adequate access to transport enables better contact with markets and facilitated access to distant and isolated outlets for higher economic opportunities. In this regard, men had a competitive advantage in accessing markets compared to women. The reasons given by respondents selected for the study were that transportation of perishable fisheries commodities was delicate and required intensive labour, travelling long distances, capital and security requirements and regular contacts on cellular phones. These were major determinants that restricted women's pursuits in competitive value chains based on socio-cultural factors; hence, subordinate to men. These findings implied that control over resources in transport sector within the fisheries value chain was entirely dependent on socioeconomic and cultural factors of entrepreneurs being reserved for men as noted in the focus group discussions:

Men succeed in coming together or getting loans to purchase trucks with refrigeration for transportation of fish in bulks. This lowers the costs of production and makes it possible for their enterprises (a woman participant in an FGD, City market, $12^{\text {th }}$ September, 2014). 
These findings were similar to (Tunde and Adeniyi, 2012) in a study in Nigeria; that control of transport sector is a crucial factor that stimulates economic growth through increased accessibility, efficiency and effectiveness.

\section{Distribution}

The distributors are important actors in the fisheries value chain. They avail the fishery commodities from the lakes and dams to market areas. It was noted that there were more men than women in fisheries value chain engaged as distributors. The City market, South C-Mugoya market and Kariobangi market had the leading proportions of 21(26.3\%) men in the respective proportions of $3(3.8 \%), 5(6.3 \%)$ and $9(11.3 \%)$ women.

The study findings indicated that distributors control the supply of fisheries commodities to actual market sellers, which demands capital and labour to own tracks with prescribed refrigeration conditions and warehouses. The study established that men have better opportunities as distributors. The reasons given were access to credit facility from microcredit and formal institutions, cooperatives and associations, competitive entrepreneurial value chain. The study findings revealed that women were not in distribution and the reasons given were informal institutions and socio-cultural factors such as customs, traditions and patriarchy; which confine women to domestic chores within their households. The respondents sampled for the study revealed that women experienced challenges in relation with bureaucracies and access to entrepreneurial information pertaining to transportation. These findings were similar to Stacy (2007) who observed that producers prefer to keep contacts with male middlemen who are traditionally believed to be the heads of the trade with adequate information concerning the flow of the trade based on business trust.

\section{Large Scale Sellers}

It was noted that in City market there were $12(40.0 \%)$ men and 2(6.7\%) women, South CMugoya only $9(30.0 \%)$ and Kariobangi market $5(16.7 \%)$ men and $2(6.7 \%)$ women participated in the value chain as large scale retailers. Large-scale retail is the bulky purchase of fish from the distributors at better discounts for processing or markets areas. Large-scale retail requires well-developed clientele, high quality of fish products, specialised labour with experience and knowledge of the market circumstances for competitive entrepreneurial participation. The findings revealed that large-scale retail requires acquisition of quality products and control of the costs. The large-scale sellers require adequate capital in order to supply in the markets variety of fish in bulk stocks from the harvesters and sufficient cash flow as working capital. Connell (1987) argued that gender division of labour, power and Cathexis structures expose women to subordination in access and control of factors of production that determines their economic activities. Therefore, the study conclusions revealed that women entrepreneurs have financial and social demands that compete with business capital and are often tempted to divert their working capital away from the business to their needs. It was also noted that women enterprises are less likely to grow to large scale or exhibit growth within the value chain compared to men. The study revealed that women compared to men within fisheries value chain face unique challenges related to capital, cash flow and the geographical area of coverage for successful participation in large-scale trade. The effects of these on their enterprises are slow growth with limited choices and opportunities that may lead to stagnation or collapse of the enterprise. These findings confirmed Wanjohi and Mugure (2008) in factors affecting the growth of MSEs in rural areas of Kenya; that despite the availability of Microfinance institutions that target entrepreneurs, men benefit as women are not able to access their services. 


\section{Grading, Sorting and Gleaning}

There were fewer men compared to women with proportions of 5(6.5\%) men and 23(29.9\%) women in City market; 3(3.9\%) men and 27(35.1\%) women in South C-Mugoya; 6(7.8\%) men and $13(16.9 \%)$ women in Kariobangi market. These findings revealed that there were more women than men within grading, sorting and gleaning in the three selected markets. The grading, sorting and gleaning were regarded as post-harvest activities where women play prominent roles in line with their reproductive roles and responsibilities were rendered as lower end value chain with marginal economic potentials. The activities related to grading, sorting and gleaning occupy the centre of interest at the market areas and include removal of scales and intestines, cleaning gills, grading and arranging the fish commodities based on the quality and size. The reasons given for the dominance of women within this category were based on the division of labour and allocation of roles within patriarchal societies where sex was the determinant. The study findings indicated that cultural beliefs were used to limit women to the post-harvest activities that included fish handling, processing and gleaning within the value chain. These findings confirm Smile (2013) a study of the state of women in fish smoking in the central region of Ghana who observed that traditionally, actual fishing is considered a men's role while women's roles were post-harvest although, these activities were less economically competitive.

\section{Sales in Market Areas}

City and South C-Mugoya markets had the leading numbers of men compared to women; while Kariobangi market had more women than men in market selling. The study findings revealed that market selling was the final stage of the value chain where consumers acquire their goods in exchange with money. From the study findings, it was observed that there were more men in City and South C-Mugoya markets, which were noted as economically viable. In contrast, women were more dominant in Kariobangi market known as less economically viable. The reasons given for this were that; men had exposure to formal education, which determined access channels to credit, information and training in management and planning sufficient to manage market areas with higher economic potentials. In line with Connell (1987), the study findings indicated that there were structural barriers that affect women's competitive entrepreneurial pursuits that limited women to lower economic zones of Kariobangi market, namely; bureaucracy, registration and licensing process, security, inadequate access to strategic information, legal institutions and policy. These findings implied that City and South C-Mugoya markets were geographically located in economic competitive zones with high entrepreneurial opportunities that attract more men than women; while on the contrast, Kariobangi market being located in a lower end economic zone; exhibited lower entrepreneurial potentials. These findings were similar to McCormick (2001) in a study on value chains and the business system in Kenya's garment industry who observed that men strategically locate their enterprises in trading centres, commercial districts or locations where enterprises are more profitable and competitive; while women prefer to operate in less profitable market areas mostly closer to their homes. The findings implied existential structural factors that prohibit women's performance within competitive markets in economic zones with higher entrepreneurial opportunities. The study respondents in entrepreneurial fisheries value chain selected for this study revealed that such factors include bureaucracy and legal procedures, inadequate institutional support in-terms of business training and skills, lack of information on market suppliers and patterns, limited access to finance due to lack of collateral and limited access to competitive markets. The study findings were similar to those of Kantor (2001) who observed that many entrepreneurs particularly women, are located in low value markets where there are lesser policy requirements for trade. Most of their entrepreneurial pursuits often in service and entertainment tend to be crowded due to fewer 
barriers. This situation results to saturated markets with little room for growth to large scale and to competitive levels of the value chain.

\section{RECOMENDATIONS}

Given poor representation of women in high end and viable ventures within the value chain, the study suggested that the government would formulate gender sensitive policies to support equal and effective participation of men and women in value chain as a livelihood and economic opportunity. Hence, provide necessary infrastructures with adequate access and utilization by men and women such as road network, electricity, security and improvement of market systems.

The study recommended that Nairobi City county government establishes a framework that checks the violence against women within the entrepreneurial practice; especially, where customs, traditions and culture were used to subordinate women's roles. This would allow the perception of women by men as equal partners and competitors in the value chain.

The study further recommended that in order to promote entrepreneurial culture, the government needs to improve the investment climate to facilitate access to finance and credit expansion for men and women in fisheries value chain, thus; to promote the borrowing culture there is need for:

- Men and women in the value chain to be trained in management of cash flow, investment and borrowing.

- The information on how to seek for credit facility needs to be availed for men and women in small micro-enterprises.

- The government needs to investigate and respond to the problems related to some financial institutions that charge more than recommended $8.0 \%$ interest rate when providing fund.

- The government ought to ensure that the lending process works favourably for women especially those in small micro-enterprises.

- Challenges related to engagement of all actors in decisions and leadership were observed; hence the study recommends that men and women in value chain enhance adequate representation in leadership that would encourage representation in decision-making process.

\section{CONCLUSION}

In conclusion, the study findings revealed that access and control of the economic and productive resources was the determinant of the ventures of entrepreneurial fisheries value chain. Since; this distribution has been influenced by gender dynamics; women potentials were noted as subordinate compared to men. Despite the fact that in City and South C-Mugoya markets, men were in market sales in most cases women were noted to participate in the lower end value chain. Kariobangi market had women as the majority entrepreneurs most of whom participated in market sales; while men were the minority and spread evenly across the ventures value chain, with majority as distributors. These findings implied trends of disparities by sex in critical areas of high end value chain across the three markets. Consequently men were in fewer numbers in Kariobangi market compared to City and South C-Mugoya market; the data indicated that men continued to be in control of the high end value chain, as women were mostly in lower end. This was attributed to Cathexis that contains women's ventures based on informal institutions (Connell, 1987). 
Kizito, P., Kimani, E., \& Lodiaga, M. (2017). Ventures Within Fisheries Value Chain that Men and Women Participate in Nairobi City County, Kenya. Advances in Social Sciences Research Journal, 4(8) 32-41.

\section{Reference}

Ajagbe, F.A. (2012). Features of small scale entrepreneurs and access to credit in Nigeria: a microanalysis. American Journal of social and management sciences. Vol. 1(51-59)

Connel, R., (1987). Gender \& Power: Society, the person and sexuality politics. Cambridge: Polity Press

De Silver (2011). Faces of women in global fisheries value chain: impact and importance in the fisheries of developed and developing countries. NORAD/FAO Value chain project.

Fauzi, A., \&Z. Anne (2010).Social resilience and uncertainties: the case of small scale fishing households in the north coast of central Java. 9: 55-64

FAO, World Fish Centre \& World Bank (2008).Small scale capture fisheries: A global overview with emphasis on developing countries. Big numbers project report Washington DC: World Bank

FAO, (2011).Womenin Agriculture: Closing the gender gap for development.Publication of Food and Agriculture Organization of the United Nations. Rome, Italy.

Gangata, K., and E.H.M. Matavire (2013).Challenges facing SMEs in accessing finance from financial institutions: The case of Bulawayo, Zimbabwe

ILO (2008).Women entrepreneurs in Kenya: Factors affecting women entrepreneurs in micro and small enterprises in Kenya Geneva: international Labour Organization

Kamau, P. And Ngigi, S. (2013).Potential for women fish traders and upgrade within the fish trade value chain: Evidence from KenyaDBA African management review. Vol.3 Nos. 2 (93-107).

Kantor, P. (2001). Promoting women's entrepreneurship development based on good practice programs: Some experiences from the North to the South. International Labour Office, Geneva-Switzerland.

Kohls, Richard L.,\&Uhl N,. Joseph, (2002).Marketing of agricultural products, 9th Ed, Prentice-Hall

Kronen M. (2003). Gender in fisheries and aquaculture: social capital and knowledge for the transition towards sustainable use of aquatic ecosystems - Case Studies from Tonga and Fiji - South Pacific.

Larney, A., and Libecap, G.D., (2000). The impact of entrepreneurship education: An evaluation of the Berger entrepreneurship program at the University of Arozona, 1985-1999. Online resource:

http://ssrn.com/abstract=1262343 or http://dx.doi.org/10.2139/ssrm.1262343 Accessed on 14th November 2014.

Lwenya C. and R. Abila(2000).The gender role in fish processing and trading practices in Lake Victoria, Kenya.

Lyn L. (1999). What is fishing? Gender, globalisation and fisheries: workshop. 6-12 May 2000. St. John's NF.

Mafimisebi, Taiwo Ejiola and Fasina, 0.0., (2009).Rural women's productivity and welfare issues: A cause for concern In: Agbamu, J.U (Ed). Perspectives in agricultural extension and rural development, Springfield Publishers Ltd., Owerri, Nigeria

Mafimisebi, TaiwoEjiola, (2007).A comparative economic analysis of two cassava-based business activities exclusive to the female gender in Oyo State, Nigeria.Journal of Agricultural Extension

McCormick, D. (2001). Value chain and the business system: Applying a simplified model to Kenyan garment industry. IDS Bulletin 32(3): 105-115.

Medard, M., K.Geheb, E. Mlahagwa, M. Kabati, D. Komba, D. Msunga, D. Ngussa, B. Zenge and U. Wabeya.(2000).Comanagerial potentials for Tanzania's Lake Victoria fisheries: Perspectives from two landing sites.In Geheb, K. (ed) (2000). Reports of the LVFRP 4 beach Survey and Stakeholders' Workshops LVFRP Technical Document. LVFRP/TECH/00/17. The Socio Economic Data Working Group of Lake Victoria Fisheries Research Project: 54-62.

Medard, M., F. Sobo, F. Ngatunga, S. Chirwa, (2000). Women and gender participation in the fisheries sector in Lake Victoria, in Williams, M.J.,Chao, H.N. and Choo, P.S. (eds).Global symposium on women in fisheries.Sixth Asian fisheries forum. Kaohsiung, Taiwan. ICLARM-The world fish centre, Penang, Malaysia (155-168).

Nayak N. (2000). Gender, globalisation and fisheries: The Indian response. Gender, globalization and fisheries workshop.6-12 May 2000, St. John's NF.

Nwabeza, G.O., P.I. Ifegika, A.A. Tafida, J.O. Oyanda, A.P. Erie, and N.E. Belonwu (2013).Gender and fisheries of lake Kainji, Nigeria: A review.Journal of fisheries and aquaculture. 8(1): 9-13.

Okorley, E.L., and Kwarten, J.A.(2006).Women in Agro-processing in Ghana: A Case Study of The State of Women in Small-scale Fish Smoking in Central Region of Ghana. University of Cape Coast, Ghana 
Ogutu, G.M.A. (ed.) (1988). Artisanal fisheries of Lake Victoria, Kenya: Options for management, production, and marketing. Proceedings of a workshop held in Kisumu, Kenya. Shirikisho Publishers for the Artisanal Fisheries (Kenya) Project, Nairobi.

Ogutu, G. E. M. (1992). Socio-economic conditions of artisanal fishermen and fish traders, p. 15-44. In G.E.M. Ogutu (ed.) (1992) Artisanal fisheries of Lake Victoria, Kenya: Options for management, production and marketing.Proceeding of a workshop held in Kisumu, Kenya.Shirikisho Publishers for the Artisanal Fisheries (Kenya) Project, Nairobi.

Omatosa, F.O. and G.A. Daramola (2005).Socio-economic factors influencing entrepreneurship among women in fisheries communities Ondo State, Nigeria.Journal of agriculture and social research.Vol. 5, No. 1, 2005.

Rosario, S., P. Gaerlan, B.L. Demely and B.D. Marine (2012).Enhancing rural women's participation in fisheries: postharvest livelihoods. Ilocos region, Philippines, Asian Fisheries Special Issue 25(5) 199-205.

Raynold, P.D. (1991). Sociology and entrepreneurship: Concepts and contributions. Entrepreneurship theory and practice. Vol. 16(2), 47-70.

Shalesha, A. and Stanley, V.A. (2000).Involvement of rural women in Agriculture: An innovation approach Naga. The ICLARM Quarterly, 23(3), 13 - 17.

Smile, D., (2013).Entrepreneurial activities of indigenous African Women: A case of Ghana. Journal of Enterprising Communities: People and places in the global economy. Volume 2.Iss (254-264)

Stacey, N., (2007).Boats to born: Bajo fishing activities in the Australian fishing Zone Asian pacific environmentmonograph 2. The Australian National University Press

Tunde, A.M. and Adeniyi, E.E (2012). Impact of Road Transport on Agricultural Development: A Nigerian Example. Ethiopian Journal of Environmental Studies and Management EJESM. Vol 5 No. 3(2012)

Wangila, B.C.C., J. Hoorweg., A.A. Degen, (2007). Gender analysis of fish traders in the central coast inshore artisanal fisheries, Kenya. Journal of science, technology education and management, volume I. 1(47-59)

Wanjohi, A.And Mugeure, A. (2008).Factors affecting the growth of SMEs in rural areas of Kenya: A case of ICT firms in Kiserian township, Kajiado District of Kenya. Journal of Small Business Management (83-87)

Williams, C. L. (2002).From women in fisheries to gender and fisheries In: Global symposium on women in fisheries Sixth Asian fisheries forum (ed) M.J. Williams et. al., Taiwan: World Fish Centre

Williams, M.J., et al (2008). Why look at fisheries through gender lens? Development Journal 51: 180-185.

World Bank (2013).World Development Indicators 2013.The world Bank Group.www.data.worldbank,org/wd/ 